\title{
Exploring the Relationship Between Boldness, Activity, Exploration and Monoaminergic Gene Expression in Red Junglefowl Chicks
}

\author{
Kristoffer A. Lundgren ${ }^{1, \#}$, Clara A. Gómez Dunlop ${ }^{1,2, \#, ~ L a u r a ~ C . ~ G a r n h a m ¹, ~ S a r a ~ R y d i n g ~}{ }^{1,2}$, Robin \\ N. Abbey-Lee ${ }^{1}$, Anastasia Kreshchenko ${ }^{1,2}$, and Hanne Løvlie ${ }^{1, *}$ \\ ${ }^{1}$ Department of Physics, Chemistry and Biology, IFM Biology, Linköping University, Sweden. \\ ${ }^{2}$ School of Biological Sciences, University of Manchester, UK. \\ \# Shared first authors \\ *Corresponding author (Email: hanne.lovlie@ liu.se)
}

Citation - Lundgren, K.A., Gómez Dunlop, C.A., Garnham, L.C., Ryding, S., Abbey-Lee, R.N., Kreshchenko, A., \& Løvlie, H. (2021). Exploring the relationship between boldness, activity, exploration and monoaminergic gene expression in red junglefowl chicks. Animal Behavior and Cognition, 8(2), $124-137$. https://doi.org/10.26451/abc.08.02.03.2021

\begin{abstract}
Why individuals differ in behavioral responses has received intense research attention (particularly in the context of animal personality), and has typically focused on describing variation in boldness, activity, and exploration. Nevertheless, the mechanisms underlying this behavioral variation remain largely unknown. Variation in these behaviors is likely influenced by genetic differences between individuals, with genes in the monoaminergic systems commonly implicated. When examining the link between variation in boldness, activity and exploration and genes, studies have focused on different monoaminergic systems (mainly serotonergic and dopaminergic), and predominantly on mammals and passerine birds. Therefore, to replicate this general approach and examine if genes from these systems are linked to boldness, activity, and exploration, we exposed red junglefowl chicks (Gallus gallus) to behavioral assays (measuring boldness, activity, exploration) before analyzing prefrontal cortex gene expression of several dopaminergic (DRD1, DRD2) and serotonergic genes (TPH, 5HT2A, 5HT2B, 5HT2C, 5HT1B). We observed no relationships between our measured behaviors and gene expression. Together with previous studies, our results suggest that a clear link between boldness, activity and exploration and monoaminergic gene variation is lacking. We, therefore, suggest that this is due to differences among studies (e.g., methodological differences), or that the nature of the relationship between these behaviors and monoaminergic systems is more species-specific, and/or more complex than so far assumed.
\end{abstract}

Keywords - Activity, Animal behavior, Boldness, Exploration, Dopamine, Gallus gallus, Serotonin

Individual variation in behavior, particularly consistent between-individual differences in behavioral responses (a.k.a. animal personality, Dall et al., 2004; Réale et al., 2007), has attracted increased research focus and is now well-established across all taxa (Carere \& Maestripieri, 2013; Gosling, 2001). Research on this topic has typically focused on the behaviors: boldness (the propensity to take risks; Wilson et al., 1994), activity (general locomotion, Réale et al., 2007), and exploration (locomotion in a novel environment, Réale et al., 2007). Despite this research attention, the mechanisms underlying such behavioral variation are still poorly understood, although underlying genetic variation is predicted (reviewed in Dochtermann et al., 2015; van Oers et al., 2005). Confirming this, variation in these behaviors is somewhat heritable (Dochtermann et al., 2015; e.g., boldness: great tits, Parus major, van Oers et al., 2005; zebrafish, Danio rerio, Ariyomo et al., 2013; exploration: great tits, Dingemanse et 
al., 2002; Drent et al., 2003), supporting the expected genetic contribution to observed individual variation. Nevertheless, it is unclear which specific genes or neurological systems underlie these relationships, as well as the generality of patterns observed in single studies or species.

Variation in monoaminergic systems, in particular the serotonergic and dopaminergic systems, is generally associated with behavioral differences (Swallow et al., 2016; Winberg \& Nilsson, 1993). In humans and nonhuman animals, serotonin, and by extension serotonin receptors, are essential in modulating a wide variety of behavioral processes (e.g., aggression, impulsivity, Soubrié, 1986). All human brain regions express serotonin receptors, albeit in a subtype-specific manner (Mengod et al., 2006), and thus, the large role serotonin plays in behavioral processes is unsurprising. The serotonergic receptors researched in our study are implicated in various behavioral functions (e.g., 5HT1B in aggression, de Boer \& Koolhaas, 2005; 5HT1B in anxiety, Tatarczyńska et al., 2004; 5HT2A in anxiety, Schreiber et al., 1998; 5HT2A; 5HT2C in addiction, Bubar \& Cunningham, 2006; 5HT2B in anxiety, Kennett et al., 1998). Dopamine and dopamine receptors are also heavily involved in explaining variation in behavior. Specifically, both D1 and D2 receptors, the most widespread and expressed of the dopaminergic receptors, are associated with modulating locomotor behavior (Baik et al., 1995; reviewed in Vallone et al., 2000). Therefore, variation in serotonergic and dopaminergic systems could also explain variation in boldness, activity, and exploration.

The main focus of research exploring links between individual variation in animal behavior and monoaminergic systems has centered on boldness, activity, and exploration. This research has shown that manipulation of serotonin levels altered boldness and activity (boldness, three-spined sticklebacks, Gasterosteus aculeatus, Abbey-Lee et al., 2019; activity, Mediterranean field crickets, Gryllus bimaculatus, Abbey-Lee, Uhrig, Garnham, et al., 2018), and manipulation of dopamine levels affected novelty-seeking and exploration (reviewed in Caramaschi et al., 2013). This supports the broader assumption of serotonergic and dopaminergic systems being influential in the expression of these behaviors.

In studies investigating more specifically how genes of the serotonergic system are associated with behavioral variation (compared to e.g., circulating levels of serotonin or its metabolite), a hypothesis-driven candidate gene approach is typically used, focusing on only a handful of genes (reviewed in Carere \& Maestripieri, 2013; Savitz \& Ramesar, 2004; van Oers et al., 2005; van Oers \& Mueller, 2010; van Oers \& Sinn, 2013). Studies on animal models for monoaminergic-related human diseases (e.g., Parkinson's) can provide further insight into potential candidate genes that may also underlie ecologically relevant behaviors (e.g., De Deurwaerdère et al., 2013). Together, these approaches show an association between polymorphisms in the serotonin transport gene (SERT/SLC6A4) and anxiety (e.g., fearful or shy behavior) observed in birds, humans, mice, rats, and primates (Eley \& Plomin, 1997; Gordon \& Hen, 2004; Munafo et al., 2009; Reif \& Lesch, 2003; Suomi, 2006; van Oers et al., 2005). Adding to this, SERT knockout mice (Mus musculus) had reduced activity and exploration in noveltybased tasks, suggesting that they were more anxious, compared to wild type mice (Kalueff et al., 2006). Polymorphisms in SERT were associated with risk-taking in dunnocks (Prunella modularis, Holtmann et al., 2016) and novelty-seeking in great tits (Parus major, Riyahi et al., 2015), suggesting increased boldness and exploration explained by SERT polymorphisms. On the other hand, these polymorphisms did not link to variation in similar behaviors in Seychelle warblers (Acrocephalus sechellensis, Edwards et al., 2015). Other suggested, but less explored, candidate genes for variation in behaviors include 5HT2A and 5HT2C receptor genes (e.g., Golimbet et al., 2002; Heisler \& Tecott, 2000; Savitz \& Ramesar, 2004; van Oers et al., 2005). For example, 5HT2A has been linked to lowered anxiety in humans (Golimbet et al., 2002); however, others have found no such relationship between 5HT2A and behavior (Kusumi et al., 2002). Also, 5HT1B may be relevant to variation in behavior, evidenced by the finding that knockout mice increased their exploration compared to wild mice (Malleret et al., 1999). With varying results from studies exploring the link between serotonergic genes and the serotonergic system, it becomes clear that this relationship overall differs among studies.

Similarly unclear results are obtained when comparing behavioral variation and dopamine receptor genes. Most studies exploring such links focus on the association between polymorphisms of 
dopaminergic D4 receptor genes (DRD4), and novelty seeking and exploration in passerine birds (great tits: Fidler et al., 2007; Korsten et al., 2010; Riyahi et al., 2015; van Oers \& Müeller, 2010; dunnocks: Holtmann et al., 2016; but see Garamszegi et al., 2014 for links between DRD4 and other aspects of animal behavior in collared fly catchers, Ficedula albicollis; and Ebstein et al., 1997; Munafo et al., 2008; Schinka et al., 2002; for associations between DRD4 and human behavior). However, not all studies that explored a link between polymorphisms in DRD4 and behavior found an association. For example, in great tits, this association was detected in only one out of four European populations (Korsten et al., 2010; Mueller et al., 2014), or no such association was detected (Riyahi et al., 2015). When exploring links between other genes of the dopaminergic system and behavior, dopaminergic D2 receptor knockout mice used as Parkinsonian animal models, showed reduced locomotor activity (Baik et al., 1995), and pharmacological interventions affecting D2 receptors resulted in altered boldness in three spined sticklebacks and Mediterranean field crickets (D2 agonism increased boldness, and D2 antagonism reduced it; fish: Abbey-Lee et al., 2019; crickets: Lundgren et al., 2021). In chickens, pharmacological manipulations of both D1 and D2 receptors affected aggression (Gallus g. domesticus; Dennis \& Cheng, 2011). Other dopamine receptors are also suggested to play a role in behavioral variation (van Oers et al., 2005). Further, the expression of specific genes appears to be linked to more than one behavioral trait. For example, gene expression of DRD1 and DRD2 is associated with different aspects of behavior in red junglefowl (optimistic behavior: Boddington et al., 2020; impulsive behavior: Ryding et al., 2021). However, the relationship between D1 and D2 receptors and boldness, activity, and exploration is, as far as we find, not yet explored.

Taken together, previous work suggests that both serotonergic and dopaminergic systems can underlie variation in animal behavior, including boldness, activity, and exploration. However, the current literature is biased towards a focus on mammals for studies on SERT (Gordon \& Hen, 2004; Monafo et al., 2009; Reif \& Lesch, 2003), and great tits for studies focusing on DRD4 (Fidler et al., 2007; Korsten et al., 2010; Mueller et al., 2014; Riyahi et al., 2015), which limits our general understanding of these links. Further, very few studies have simultaneously investigated how several genes from the serotonergic and dopaminergic systems may link to variation in a range of behavior (van Oers \& Mueller, 2010; but see e.g., Abbey-Lee, Uhrig, Garnham, et al. 2018; Abbey-Lee et al., 2019; Edward et al., 2015; Holtmann et al., 2016; Riyahi et al., 2015; Lundgren et al., 2021).

Therefore, to both replicate the generally expected associations between monoaminergic systems and variation in behavior, and expand upon previous work in terms of genes and by using a species outside the common model organisms used when studying the relationship between monoamines and behavior, we investigated associations between genes of the serotonergic system (TPH, 5HT1B, 5HT2A, 5HT2B, 5HT2C) and dopaminergic system (DRD1, DRD2) with variation in boldness, activity, and exploration, in the red junglefowl (Gallus gallus). Red junglefowl in captivity easily habituate to human presence and handling, and are commonly used in behavioral research (e.g., Favati et al., 2016; Zidar, Balogh, et al., 2017, Zidar, Sorato, et al., 2017, Zidar, Balogh, et al., 2018, Zidar, Campderrich, et al., 2018; reviewed in Garnham \& Løvlie, 2018). We chose to here compare behavioral variation and gene expression. Gene expression analyses allow investigation of the molecular mechanisms underlying behavior and can provide insight into the function and variation of genetic contribution to observed behavioral variation (reviewed in Bell \& Aubin-Horth, 2010; van Oers \& Mueller, 2010). Comparing behavioral variation with gene expression is different from comparisons with gene polymorphisms, but similar in that both methods can be used to focus on candidate genes with an a priori predicted link to studied behaviors. Additionally, both methods give similar general information on whether there is evidence for a relationship between a specific behavior and gene. The genes 5HT1B, 5HT2C, and DRD2 were chosen because earlier studies in other species suggest an association between these genes and variation in exploration, activity, or boldness, respectively (Abbey-Lee et al., 2019; Heisler \& Tecott, 2000; Malleret et al., 1999; van Oers et al., 2005). Based on this, we predicted that exploration and activity would be negatively correlated with gene expression of 5HT1A and 5HT1B, whilst exploration and boldness would be positively correlated with DRD2. The associations between boldness, activity, and exploration, and TPH (serotonin synthesizer), 5HT2A, 5HT2B, 5HT2C and DRD1 have not yet been 
investigated and we, thus, had no a priori predictions on their relationships. These genes were included here as they play a role in other aspects of behavior (e.g., sociability, aggression: de Boer \& Koolhaas 2005; de Souza et al., 2020; impulsivity: Ryding et al., 2021) and are candidate genes of the same monoaminergic system as previous studied in other species.

\section{Method}

\section{Animals and Housing}

Thirty-three $\left(n_{\text {females }}=14, n_{\text {males }}=19\right)$ red junglefowl chicks from a larger population maintained at Linköping University, were used in 2017 for this study. This population is pedigree bred (details in Sorato et al., 2018) with the aim to maintain genetic diversity. To reduce maternal effects, chicks were hatched in artificial incubators and, to facilitate identification, wing-tagged with unique numbers upon hatching. Chicks were housed in mixed-sex groups ( $\leq 25$ individuals) in six identical cages $(72 \times 71 \mathrm{x} 53 \mathrm{~cm}, \mathrm{~L} \times$ $\mathrm{W} \times \mathrm{H}$ ) equipped with perches, heaters, light ( $7 \mathrm{am}$ to $7 \mathrm{pm}$ ) and with ad libitum commercial poultry feed and water. Chicks did not have designated home cages and were moved between cages throughout the experiment. The experiment was carried out in accordance with Swedish ethical requirements (Linköping Ethical Committee, ethical permit numbers 50-13).

\section{Experimental Set-Up}

All chicks were tested individually, had previously taken part in behavioral studies, and were habituated to human handling and temporary isolation during testing (Boddington et al., 2020; Ryding et al., 2021).

\section{Novel Arena and Novel Object Tests}

To measure variation in boldness, activity, and exploration, behavioral responses to a novel environment and a novel object were used (Réale et al., 2007). From days 28-30 of age, behavioral measures were taken of individual chicks in a novel arena test $(114$ x 76 x $40 \mathrm{~cm}$; L x W x H, sensu Zidar, Balogh, et al., 2017). To encourage exploration, the arena had empty water bells (dome-shaped, $20 \times 19.5$ $\mathrm{cm}, \varnothing \times \mathrm{H})$ to prevent the chick from seeing the entire arena from any location (Zidar, Balogh, et al., 2017). Both the novel arena test, and the novel object test (described below), lasted $10 \mathrm{~min}$, with the novel arena test done immediately before the novel object test. Both tests were video recorded, and behavioral data was obtained later from these videos. In the novel arena test, boldness was measured as latency (in seconds) for a chick to take its first step (i.e., latency to move, Réale et al., 2007) after it was placed in the arena (a shorter latency indicated bolder individuals). Once a chick started moving, we recorded activity, measured as the number of times a chick moved between six imaginary equal sized sub-areas in the arena, and exploration as latency (in seconds) for a chick to visit all sub-areas in the arena. Chicks that did not explore all sub-areas were given the maximum time of $600 \mathrm{~s}$. Only one individual out of our tested birds was given a value of 600 . Therefore, the cut off at $600 \mathrm{~s}$ did not have any major impact on our results. For exploration, a shorter latency indicated more explorative, thus faster exploring, individuals. Following the novel arena test, the lights were turned off and a novel object placed in the same arena as far as possible from, whilst still visible to the chick (between ca $60-120 \mathrm{~cm}$ from the chick, depending on the position of the chick). The novel object was a stuffed toy with big eyes (ca $10 \mathrm{~cm} \varnothing+10 \mathrm{~cm}$ long tail), likely perceived by the chicks as a predator and, thus, threatening (Greggor et al., 2015). The lights were turned on and the test started. Boldness and activity were again observed for $10 \mathrm{~min}$, but not exploration, as this is recommended to be measured in a novel arena (Réale et al., 2007). Since previous studies on earlier cohorts of the same population have shown these variables to be consistent within individuals over repeated measures (e.g., Favati et al., 2016; Zidar, Balogh, et al., 2017, Zidar, Sorato, et al., 2017), we do not believe that variation in the placement of the novel object affected the results here presented. 


\section{Tonic Immobility}

Chicks were exposed to a tonic immobility test used in poultry research to measure fearfulness (Forkman et al., 2007), which relates to bold-shy axis as shyer individuals are considered more fearful (Réale et al., 2007). To prevent any effect of differences in handling, and to minimize human influence, all chicks were tested by the same observer (SR) who avoided eye contact with them during the test. To induce tonic immobility, the observer placed the chick on its back in a cradle and gently held it down with one hand over the chest and the other hand over the head (sensu Zidar, Balogh, et al., 2017). After $15 \mathrm{~s}$, the observer slowly lifted their hands and tonic immobility was considered induced if the chick remained on its back for at least $3 \mathrm{~s}$. Fearfulness was measured as the time (in seconds) a chick took to stand upright again after tonic immobility had been induced, with longer latency indicating a higher level of fearfulness (Forkman et al., 2007). Also, this measure has previously been shown to be consistent within individuals when repeatedly tested (e.g., Favati et al., 2016). If a chick did not enter tonic immobility after a maximum of three attempts to induce this, it was given a tonic immobility latency of $0 \mathrm{~s}$. Chicks that did not come out of tonic immobility within $600 \mathrm{~s}$ were given a latency of $600 \mathrm{~s}$. Only one of our tested individuals was given a maximum value of $600 \mathrm{~s}$; thus, using max latencies should have no effect on the obtained results.

\section{Gene Expression Analyses}

To examine the relationship between brain gene expression of serotonergic and dopaminergic genes and our behavioral measures, we culled the behaviorally assayed chicks at 9 weeks of age, by rapid decapitation and dissected out their brains. The caudal region of the left telencephalon was extracted and snap frozen in liquid nitrogen $(\leq 4 \mathrm{~min})$ and stored at $-80^{\circ} \mathrm{C}$ until RNA extraction. This area was chosen as it contains the nidopallium (the avian analogue of the mammalian prefrontal cortex), and the left hemisphere is the dominant hemisphere, suggested to be involved in variation in behavior (Coppens et al., 2010).

To extract RNA, we used Ambion TRI Reagent (Life Technologies, USA) according to the manufacturer's instructions. To measure the extracted RNA, we used a Nanodrop 1000 (Thermofisher, Sweden) for all samples, and the quality of RNA was measured using Agilent 2100 Bioanalyzer for a subset of 12 samples. Our samples were not degraded, shown by that all RNA integrity number values were above 9. Single-stranded cDNA was prepared using Maxima First Strand cDNA Synthesis Kit with DNase (Thermo Fisher Scientific, USA) using $1 \mu \mathrm{g}$ total RNA as template. Our primers targeted POL2 and TBP for housekeeper genes chosen based on previous work on red junglefowl (Elfwing et al., 2014), dopamine receptors DRD1 and DRD2, serotonin receptors 5HT1B, 5HT2A, 5HT2B, and 5HT2C, and serotonin synthesizer TPH (supplementary Table S1). To ensure primer specificity, the melting curve ran on pooled cDNA from all individuals, was examined. Each $10 \mu 1$ reaction volume used for the qPCR contained $1 \mu \mathrm{l}$ of equal parts forward and reverse primer, 60-80 picograms of cDNA diluted in $2 \mu 1$ water, $5 \mu \mathrm{l} \mathrm{SYBR}$ Green I Master (Roche Diagnostics, Switzerland), and $2 \mu 1$ water. The qPCR was performed in a Light Cycler 480 (Roche Diagnostics, Switzerland) at 5 min $95{ }^{\circ} \mathrm{C}$ for activation, succeeded by 40 cycles $\left(10 \mathrm{~s} 95^{\circ} \mathrm{C}, 10 \mathrm{~s} 60{ }^{\circ} \mathrm{C}\right.$, and $\left.20 \mathrm{~s} 72{ }^{\circ} \mathrm{C}\right)$. The end of the program ran a melting curve from $72{ }^{\circ} \mathrm{C}$ to $95^{\circ} \mathrm{C}$, before cooling to $40{ }^{\circ} \mathrm{C}$.

We had to eliminate one plate (plate 1, out of 22) from the analysis due to a calibration error during PCR. For all others, the crossing point $(\mathrm{Cp})$ values over the two housekeeping genes were calculated. Samples were run in duplicate, and the average expression was calculated for each individual based on these two $\mathrm{Cp}$ values $(\mathrm{CV}=15.70 \%)$. Expression levels of the genes of focus were calculated for each individual by the difference in expression between the housekeeper genes and the gene of interest ( $\Delta \mathrm{Cp}$, where higher $\Delta \mathrm{Cp}$ values signify lower gene expression). 


\section{Statistical Analyses}

$\mathrm{R}$ version 4.0.1 ( $\mathrm{R}$ Core team, 2020) was used for statistical analyses. Our behavioral measures (of boldness, activity, and exploration) did not follow the assumptions needed for parametric statistics, so we used non-parametric statistical analyses throughout. Red junglefowl are sexually dimorphic, and sex differences in behavior have been observed previously in our population (e.g., Zidar, Balogh, et al., 2018), and in patterns of association between monoaminergic systems and behavior in other avian species (e.g., Holtmann et al., 2016). Therefore, we examined whether behavioral measures and gene expression levels differed between the sexes using Mann-Whitney U tests. Gene expression levels of DRD1 differed between the sexes (see results). Thus, sex differences in the correlations between DRD1 expression and each behavioral measure were visually inspected. These relationships were not in the same direction for boldness in a novel arena, exploration, and tonic immobility (i.e., one sex showed a positive correlation between behavior and DRD1 expression whilst the other sex showed a negative correlation between behavior and DRD1 expression). Therefore, data from each sex was, for these behaviors, analyzed separately since pooling the data when the pattern differed between the sexes would mask such differences. All our other variables did not differ in direction of correlations among sexes, and data from both sexes was, therefore, pooled for further analyses.

To check the interrelatedness of our behavioral measures, and associations between these and gene expression levels, we used Spearman rank correlations. To control for type I errors, presented $p$ values are Bonferroni corrected. As some chicks did not complete all tests (due to them failing to be habituated to partake in the tests alone) and since sexes were analyzed separately for some behaviors/genes (described above), sample sizes vary somewhat between comparisons $(n=14-32)$. Due to the presence of some extreme values in 5HT2A expression in our comparisons, all analyses were run with and without these values, which somewhat altered the direction of some relationships (Supplementary Information, Figures S1-S6). Results for 5HT2A without these extreme values, are presented here.

\section{Results}

\section{Effect of Sex}

Overall, sexes did not differ in our behavioral measures, nor in gene expression levels, except for a tendency for higher gene expression of DRD1 in males compared to females (Table 1).

\section{Correlation Between Behavioral Measures}

Activity in a novel arena (where a higher score describes more active individuals) positively correlated with activity in the presence of a novel object $\left(n=32, r_{\mathrm{s}}=.82, p<.001\right)$, and negatively with exploration in a novel arena (where a shorter exploration latency describes more explorative birds, $n=32$, $\left.r_{\mathrm{s}}=-.61, p=.02\right)$. Activity in the presence of a novel object negatively correlated with exploration in a novel arena ( $n=32, r_{\mathrm{s}}=-.55, p=.02$; i.e., more active individuals were also bolder). Other behavioral measures did not correlate (all $n=31-32, r_{\mathrm{s}} \leq \pm .20, p \geq .43$ ).

\section{Behavioral Measures and Brain Gene Expression}

Expression of none of the genes we examined correlated with any of the behavioral measures obtained (all $n=14-32, r_{\mathrm{s}} \leq \pm .42, p>.58$, Table 2). DRD2 showed a moderate relationship with activity in a novel arena $\left(n=32, r_{\mathrm{s}}=-.30, p=.09\right.$, Figure 1). However, after applying Bonferroni corrections this comparison was non-significant. 
Table 1

Comparison Between Male and Female Red Junglefowl Chicks in Behavioral Measures and Gene Expression

\begin{tabular}{lcccc}
\hline & $\begin{array}{c}\text { Male } \\
\text { Mean }( \pm \mathbf{S E})\end{array}$ & $\begin{array}{c}\text { Female } \\
\text { Mean }( \pm \mathbf{S E})\end{array}$ & W-value & $\boldsymbol{p}$-value \\
\hline Behavioral score & & & & \\
$\quad$ Boldness NA & $12.33(3.01)$ & $11.00(3.07)$ & 120.50 & .84 \\
Activity NA & $82.33(16.06)$ & $55.64(8.33)$ & 104.50 & .42 \\
Exploration NA & $219.39(28.01)$ & $296.57(46.83)$ & 149.50 & .38 \\
Boldness NO & $31.67(5.57)$ & $52.00(9.95)$ & 172.00 & .08 \\
Activity NO & $104.11(17.01)$ & $59.43(10.82)$ & 82.00 & .09 \\
Latency TI & $98.89(33.96)$ & $31.67(10.61)$ & 72.00 & .09 \\
\hline Gene expression & & & & \\
DRD1 & $23.84(0.16)$ & $23.51(0.07)$ & 86.00 & .09 \\
DRD2 & $29.05(0.31)$ & $28.46(0.26)$ & 99.50 & .22 \\
5HT1B & $22.59(0.18)$ & $22.20(0.09)$ & 90.50 & .13 \\
5HT2A & $26.41(0.22)$ & $26.14(0.18)$ & 103.00 & .67 \\
5HT2B & $26.39(0.15)$ & $27.60(0.97)$ & 128.50 & .88 \\
5HT2C & $24.35(0.15)$ & $24.04(0.12)$ & 99.00 & .22 \\
TPH & $32.78(0.24)$ & $32.53(0.44)$ & 131.50 & .97 \\
\hline
\end{tabular}

Note. "Boldness NA" is the latency in seconds to a chick's first step in a novel arena, "Activity NA" is the number of transitions between sub-areas in a novel arena, "Exploration NA" is the latency to explore all sub-areas of a novel arena, "Boldness NO" is the chick's latency in seconds to take a step after placing a novel object inside the arena, "Activity NO" is the number of transitions between sub-areas in a novel arena test, "Latency TI" is latency in seconds for a chick to stand up after tonic immobility had been induced, "DRD1" and "DRD2" are dopaminergic receptors, "5HT1B", "5HT2A", "5HT2B" and "5HT2C" are serotonergic receptors, "TPH" is a serotonin synthesizer. $n_{\text {females }}=14, n_{\text {males }}=19$ for all gene expressions except "5HT2A" $\left(n_{\text {females }}=12, n_{\text {males }}=19\right), n_{\text {females }}=14, n_{\text {males }}=18$ for all behavioral measures except "Latency TI" $\left(n\right.$ females $\left.=12, n_{\text {males }}=19\right)$. Mann-Whitney U-value and corresponding $p$-value, are given.

Table 2

Relationships Between Behavioral Measures and Brain Gene Expression in Red Junglefowl Chicks

\begin{tabular}{lcccccc}
\hline Gene/Behavior & Boldness NA & Activity NA & Exploration NA & Boldness NO & Activity NO & Latency TI \\
\hline DRD1 & $-.15 \mid .08$ & -.07 & $.30 \mid-.30$ & .26 & -.15 & $.42 \mid-.20$ \\
DRD2 & .07 & -.30 & .03 & .07 & -.28 & .15 \\
5HT1B & .17 & -.17 & .18 & -.01 & -.23 & -.09 \\
5HT2A & -.01 & -.17 & .07 & -.24 & .03 & .19 \\
5HT2B & -.10 & -.08 & .04 & -.25 & -.12 & .07 \\
5HT2C & .16 & .11 & -.08 & .05 & -.08 & .09 \\
TPH & -.11 & & & & .19 & \\
\hline
\end{tabular}

Note. "Boldness NA" is the latency in seconds to a chick's first step in a novel arena $\left(n=32\right.$, DRD1: $\left.n_{\text {female }}=14, n_{\text {male }}=18\right)$, "Activity NA" is the number of transitions between sub-areas in a novel arena $\left(n=32\right.$, DRD1: $\left.n_{\text {females }}=14, n_{\text {males }}=18\right)$, "Exploration NA" is the latency to explore all sub-areas of a novel arena $\left(n=32\right.$, DRD1: $\left.n_{\text {females }}=14, n_{\text {males }}=18\right)$, "Boldness NO" is the chick's latency in seconds to take a step after placing a novel object inside the arena $(n=32)$, "Activity NO" is the number of transitions between sub-areas in a novel arena test $(n=32)$, "Latency TI" is latency in seconds for a chick to stand up after tonic immobility had been induced ( $n=31$, DRD1: $\left.n_{\text {females }}=12, n_{\text {males }}=19\right)$, "DRD1" and "DRD2" are dopaminergic receptors, "5HT1B," "5HT2A," "5HT2B" and "5HT2C" are serotonergic receptors, "TPH" is a serotonin synthesizer. Spearman correlation coefficient $\left(R_{s}\right)$ are presented. All $p$-values were non-significant after Bonferroni correction and are not presented. “"” indicate females and males were analyzed separately, with female values presented first. 
Figure 1

The Relationship Between Activity in a Novel Arena Test and Gene Expression of DRD2 in Red Junglefowl Chicks

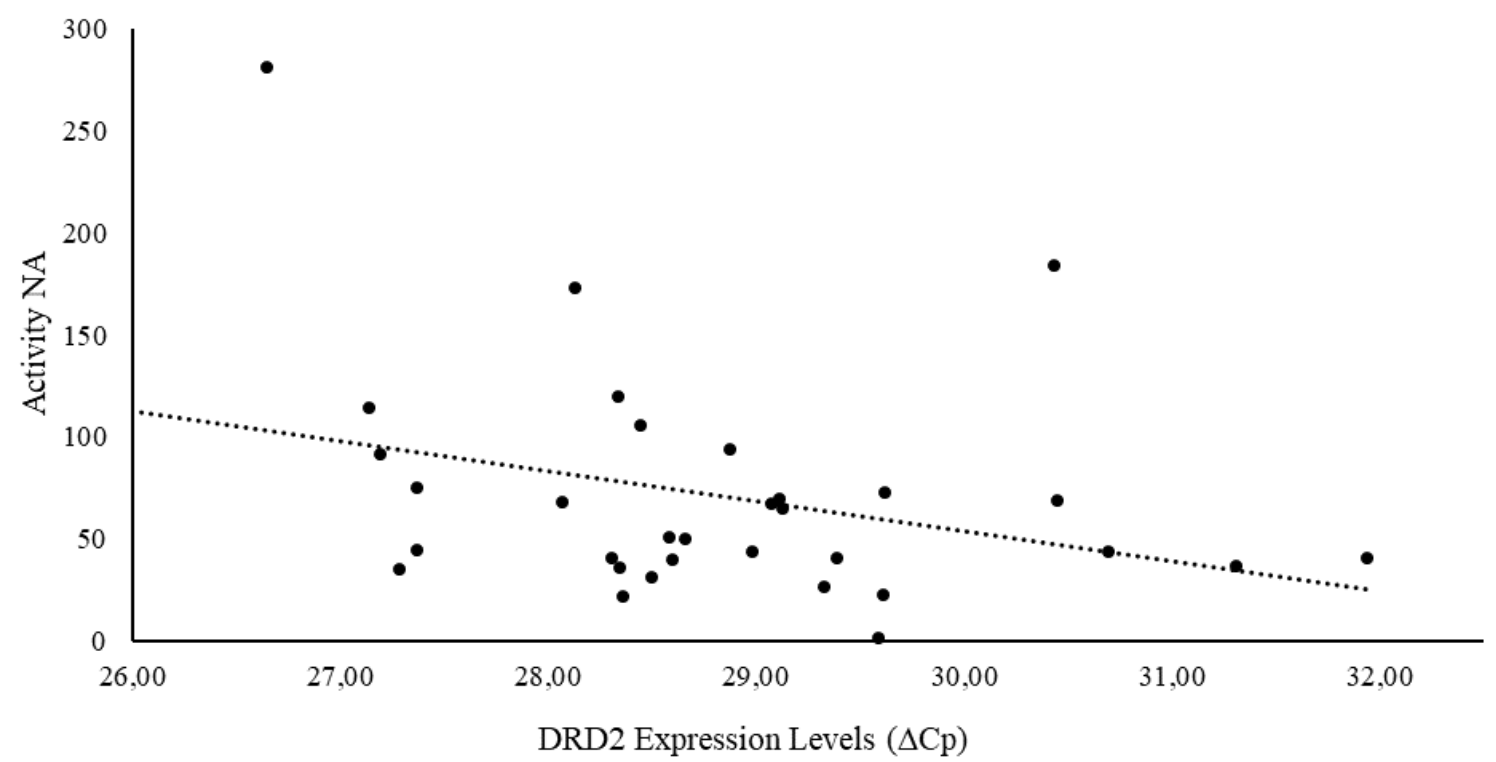

Note. "Activity NA" is the number of transitions between sub-areas in a novel arena test. Gene expression levels are measured by $\Delta \mathrm{Cp}$, which is the difference between the gene of interest and a housekeeper gene. Higher $\Delta \mathrm{Cp}$ values indicate lower expression levels. Each dot represents an individual.

\section{Discussion}

Here, we explored the relationship between variation in boldness, activity, and exploration with expression of genes from two monoaminergic systems (serotonergic, dopaminergic), in red junglefowl chicks. None of our behavioral measures associated significantly with the genes' expressions.

Our aim was to replicate previous work exploring links between boldness, activity, and exploration with candidate genes of the monoaminergic systems, and to expand this to include multiple behaviors and more genes (beyond the common focus on SERT and DRD4) and focus on a species not yet investigated in this context. Several studies have shown some link between either the serotonergic or dopaminergic system, and some aspect of these behaviors or similar behavior. However, studies have rarely investigated both systems simultaneously, and rarely explored their links with multiple behaviors (but see e.g., Edwards et al., 2015 and Holtmann et al., 2016 for exploring two genes, or Garamszegi et al., 2014 for exploring one gene and several behavioral variables). Nevertheless, collectively, there is accumulated support for genetic variation in both systems underlying, at least some, behavioral variation (e.g., van Oers et al., 2005; van Oers \& Mueller, 2010). However, we here found no significant associations between expression of explored serotonergic and dopaminergic genes with boldness, activity, or exploration.

Research into the genetic variation underlying human behavior has mostly focused on the relationship between DRD4 and approach-related behavioral traits (e.g., novelty-seeking) and, overall, has found no strong association (Munafo et al., 2008). However, DRD4 has been associated with impulsivity-related traits (Balestri et al., 2014). The serotonergic system through SERT has been reliably associated with anxiety (Balestri et al., 2014), although polymorphism in the serotonin transport gene (SLC6A) shows a weak link to anxiety-related traits (Munafo et al., 2009). The mixed, and overall, weak patterns of gene variation in the monoaminergic systems and human behavior, mirrors patterns observed both within and across other animal species. If focusing only on research on great tits, the animal species with the most studies published on associations between variation in behavior and polymorphism of 
monoaminergic genes to date, we find these to show population differences and thus, no strong overall associations (Korsten et al., 2010; Mueller et al., 2014; Riyahi et al., 2015).

Our results add to previous studies showing a lack of an association between behavioral variation and genetic variation in the monoaminergic systems (e.g., Edwards et al., 2015). Considering the expected polygenetic contribution to complex behavior, such as personality traits, a lack of strong associations between specific genes and variation in behavior is not very surprising and, instead, a small contribution of many genes to behavioral variation is expected (van Oers \& Mueller, 2010).

In addition, there are both known and unknown differences in subjects recruited for previous studies on monoamines and behavior (e.g., age and sex of subjects; wild vs. captive populations), which can further explain the overall weakly observed relationships between monoaminergic systems and behavior. In our study, we included both male and female chicks, of the same age, from a captive population. The use of a captive population avoids the common bias in wild-caught individuals where participation in behavioral tests is biased towards bolder and more easily caught individuals, and against shy and less explorative individuals. On the other hand, captive populations differ from wild populations, making it potentially more challenging to directly compare our findings with other avian studies (which have focused only on wild passerine birds, e.g., Fidler et al., 2007; Holtmann et al., 2016; Korsten et al., 2010). These differences can entail reduced genetic variation of captive populations (although our population originates from a mix of two wild-caught populations, and our pedigree maximizes family differences, see Sorato et al., 2018 for details), lack of direct natural selection (although our population face some unintended parasite and pathogen outbreaks), and greater food availability, and thus reduced food competition, in captive populations compared to wild populations.

This special issue discusses the value and status of replication in animal behavior research. In our work, we see many studies that aim to identify the underlying molecular mechanisms of behaviors, but the techniques for measuring and quantifying both the behaviors and the mechanisms vary between studies. Thus, there is often an obfuscation of true replication in the field as many authors work to make comparisons amongst studies using different methods. Despite great efforts in the field to reach a consensus in how aspects of behavior are measured (at least in the framework of describing animal personality, e.g., Dall \& Griffith, 2014; Réale et al., 2007), the behavior observed can both differ among studies, and have different ecological and evolutionary implications across species (Réale et al., 2007; Smith \& Blumstein, 2008). Further, the different ways the role of monoaminergic systems in behavior have been explored cause further variation across studies. The monoaminergic systems are complex and interact both among themselves (e.g., 5HT2C receptors interacting with the dopaminergic system), and with other important aspects of physiology (e.g., stress responses). These multifaceted systems depend on a synergy of several chemicals and the combined function of synthesizers, producers, transporters, and receptors to influence the circulating levels of monoamines and their turnover rates (Winberg \& Nilsson, 1993). The two main pathways for genetic control of behavior studied are through variation in gene expression and gene polymorphism. Both methods have been used to demonstrate a link between the monoaminergic systems and the behaviors we measured here. Studies on variation in gene expression have manipulated circulating levels of monoamines and/or looked at links between natural levels and behavior (Abbey-Lee, Uhrig, Garnham, et al., 2018; Abbey-Lee et al., 2019). Gene polymorphism studies involve knocking down a specific gene (e.g., Kalueff et al., 2006; Malleret et al., 1999), or looking at gene polymorphisms in either producing, transporting or receptor genes (e.g., Fidler et al., 2007; Holtmann et al., 2016; Korsten et al., 2010; Suomi, 2006). An important difference amongst these types of studies is the time frame and flexibility of the variation, as well as the causality of the findings. SNPs, gene polymorphisms, and genetic variation among individuals describe consistent variation over individuals' lifetimes and operate more deterministically than gene expression. Studies on polymorphisms and among individual variation can suggest candidate genes for the observed differences in behavior but cannot show causation unless using knock out studies (van Oers \& Mueller, 2010). Gene expression studies, on the other hand, show a snapshot of the current molecular environment of an individual. As expression of different monoamines can be manipulated, these studies can directly show causal effects. Using a combination of SNP studies to identify candidate genes, gene expression manipulations, and 
knock out approaches allows for investigation of the molecular mechanisms underlying behavior and can, therefore, provide insight into the functionality and variation of genetic contribution to observed behavioral variation (reviewed in Bell \& Aubin-Horth, 2010; van Oers \& Mueller, 2010). Although these different approaches can generally show (or dismiss) a link between monoaminergic systems and variation in behaviors, the use of different approaches could also explain why different patterns are observed across studies. Thus, one hurdle for replication in the field of animal behavior research is the multifaced aspect of the monoamine systems, where true replication of both behavioral and molecular methods is rare.

Differences can even occur in studies that have all explored gene expression and that investigate the same organ (typically brains), mainly due to differences in the brain area studied, as well as differences in brain differentiation across study species (e.g., Kubikova et al., 2010; von Eugen et al., 2020). When comparing our results to other studies on gene expression and links with the behavior explored here, some studies do find links. For example, bolder Atlantic salmon (Salmo salar) had higher gene expression of 5HT1A receptor (measured in front brains; Thörnqvist et al., 2015). Further, in male mice (but not females) infected with toxoplasma, DRD4 gene expression was upregulated, but did not translate into differences in activity levels (measured in frontal cortex; Xiao et al., 2012). In three-spined stickleback (Gasterousteus aculeatus) several candidate genes of the serotonergic and dopaminergic systems linked to behavior used to describe activity, exploration and boldness (front brain, where gene expression of 5HTR2A, 5HTR2B negatively associated with activity, while DRD2 positively associated with exploration, 5HTR2A and DRD2 expression was lower in bolder fish, while expression of 5HTR2B was higher in bolder fish, Abbey-Lee et al., 2019; but see Abbey-Lee, Uhrig, Zidar, et al., 2018, for lack of such links). Overall, studies show that even relationships between gene expression of the monoaminergic systems and behavior, are mixed.

Thus, observed patterns differ across studies. As discussed, this may be due to species differences, despite the notion that monoaminergic systems remain mainly conserved across species (Gunnarsson et al., 2008). There are also often methodological differences among studies that can, at least in part, explain differences in results, such as time between behavioral testing and gene analysis. In our current study, there was a five-week time gap between behavioral testing and gene expression analyses. Both behavioral testing and molecular analyses were carried out before the first major developmental stage in fowl (at 10-12 weeks of age; McBride et al., 1969) and we therefore do not predict this gap between testing and gene expression analysis to have had major effects on our results (except for some reduction in exploratory behavior; Favati et al., 2016). Future studies should, however, explore this further. In addition, there may exist a bias towards publishing studies that do find associations between monoaminergic systems and behaviors. Expanding further on this, there is also a bias in that more papers are published that have explored links between SERT and behavior in mammals (e.g., Gordon \& Hen, 2004; Reif \& Lesch, 2003), and DRD4 and behavior in passerines (e.g., Fidler et al., 2007; van Oers \& Mueller, 2010). There is hardly any research that has focused on other genes, or where lack of clear associations between gene expression and variation in behavior are shown. Thus, general conclusions are still hard to draw across species on a more detailed level than that the monoaminergic systems sometimes associate with behavioral variation.

\section{Conclusions}

We could not confirm the previously observed link between boldness, activity, and exploration and genes of the serotonergic and dopaminergic systems. Although the lack of expected associations may be due to limitations of our study, considering the mixed results among other studies it also raises the question of whether these associations are species-specific or differ due to the specific aspects in focus, for each study. To further explore the generality of relationships between animal behavior and monoaminergic systems, we suggest more directly replicated studies both within and across species, or a more systematic review and meta-analysis, of the current literature. 


\section{Acknowledgements}

We would like to thank Julia Buskas for animal care, Xavier Fernández Sala, Enrico Sorato, Irina Petkova for their assistance during behavioral testing, and useful comments by 2 anonymous reviewers and editor Christian Nawroth on earlier draft of the manuscript. The work was carried out within the framework of the Centre of Excellence in Animal Welfare Science. The work was funded by The Swedish Research Council FORMAS (to HL), and from NEURO (to RNAL \& HL).

\section{Competing interests}

The authors declare no competing interests.

\section{Authors' Contributions}

HL designed and coordinated the study; SR, LG, RNAL \& AK collected behavioral data; HL and RNAL dissected brains. SR, AK, \& RNAL carried out molecular analyses; CAGD carried out statistical analyses with input from HL \& KL; KL, CAGD \& HL drafted the manuscript with input from the other authors. HL funded the study. All authors gave final approval for publication.

\section{Data availability}

Data analyzed for this paper are available in Supplementary Material.

\section{References}

Abbey-Lee, R. N., Uhrig, E. J., Garnham, L., Lundgren, K., Child, S., \& Løvlie, H. (2018). Experimental manipulation of monoamines levels alters personality in crickets. Scientific Reports, 8,16211.

Abbey-Lee, R. N., Uhrig, E. J., Zidar, J., Favati, A., Almberg, J., Dahlbom, J., Winberg, S., \& Løvlie, H. (2018). The influence of rearing on behavior, brain monoamines, and gene expression in three-spined sticklebacks. Brain, Behavior and Evolution, 91(4), 201-213.

Abbey-Lee, R. N., Kreshchenko, A., Sala, X. F., Petkova, I., \& Løvlie, H. (2019). Effects of monoamine manipulations on the personality and gene expression of three-spined sticklebacks. Journal of Experimental Biology, 222(2), jeb211888.

Ariyomo, T. O., Carter, M., \& Watt, P. J. (2013). Heritability of boldness and aggressiveness in the zebrafish. Behavior Genetics, 43(2), 161-167.

Baik, J. H, Picetti, R., Saiardi, A, Thiriet, G., Dierich, A., Depaulis, A., Le Meur, M., \& Borrelli, E. (1995). Parkinsonian-like locomotor impairment in mice lacking dopamine D2 receptors. Nature, 377(6548), 424 428.

Balestri, M., Calati, R., Serretti, A., \& de Ronchi, D. (2014). Genetic modulation of personality traits: A systematic review of the literature. International Clinical Psychoparmacology, 29(1), 1-15.

Bell, A. M., \& Aubin-Horth, N. (2010). What can whole genome expression data tell us about the ecology and evolution of personality? Philosophical Transactions of the Royal Society of London. Series B, Biological Sciences, 365(156), 4001-4012.

Boddington, R., Dunlop Gomez, C. A., Garnham, L.C., Ryding, S., Abbey-Lee, R. N., Kreshchenko, A., \& Løvlie, H. (2020). The relationship between monoaminergic gene expression, learning, and optimism in red junglefowl chicks. Animal Cognition, 23, 901-911.

Bubar, M. J., \& Cunningham, K. A. (2006). Serotonin 5-HT2A and 5-HT2C receptors as potential targets for modulation of psychostimulant use and dependence. Current Topics in Medical Chemistry, 8(6), 1971-1985.

Caramaschi, D., Carere, C., Sgoifo, A. \& Koolhaas, J. (2013). Neuroendocrine and autonomic correlates of animal personalities. In C. Carere \& D. Maestripieri (Eds.), Animal Personalities (pp. 353-378). University of Chicago Press.

Carere, C. \& Maestripieri, D. (2013). Introduction: Animal personalities: Who cares and why? In C. Carere \& D. Maestripieri (Eds.), Animal personalities (pp. 1-10). University of Chicago Press. 
Coppens, C. M., de Boer S. F \& Koolhaas J. M. (2010). Coping styles and behavioral flexibility: Towards underlying mechanisms. Philosophical Transactions of the Royal Society of London. Series B, Biological Sciences, 365, 4021-4028.

Dall, S. R., Houston, A. I., \& McNamara, J. M. (2004). The behavioural ecology of personality: Consistent individual differences from an adaptive perspective. Ecology Letters, 7(8), 734-739.

Dall, S. R. X \& Griffith, S. C. (2014). An empiricists guide to animal personality variation in ecology and evolution. Frontiers in Ecology and Evolution, 2, 3.

de Boer, S. F., \& Koolhaas, J. M. (2005). 5- $\mathrm{HT}_{1 \mathrm{~A}}$ and 5- $\mathrm{HT}_{1 \mathrm{~B}}$ receptor agonists and aggression: A pharmacological challenge of the serotonin deficiency hypothesis. European Journal of Pharmacology, 526(1-3), 125-139.

De Deurwaerdère, P., Lagiere, M., Bosc, M., \& Navailles S. (2013). Multiple controls exerted by 5-HT2C receptors upon basal ganglia function: From physiology to pathophysiology. Experimental Brain Research 230(4), 477-511.

Dennis, R. L., \& Cheng, H. W. (2011). The dopaminergic system and aggression in laying hens. Poultry Science, 90(11), 2440-2448.

de Souza, J. A., da Silva, M. C., Costa, F. C. O., de Matos. R. J. B., de Farias Campina, R. C., do Amaral Almeida, L. C., da Silva, A. A. M., Cavalcante, T. C. F., Tavares, G. A., \& de Souza, S. L. (2020). Early life stress induced by maternal separation during lactation alters the eating behavior and serotonin system in middleaged rat female offspring. Pharmacology, Biochemistry, and Behavior, 192, 172908.

Dingemanse, N. J., Both, C., Drent, P. J., Van Oers, K., \& Van Noordwijk, A. J. (2002). Repeatability and heritability of exploratory behaviour in great tits from the wild. Animal Behaviour, 64(6), 929-938.

Dochtermann, N. A., Schwab, T., \& Sih, A. (2015). The contribution of additive genetic variation to personality variation: Heritability of personality. Philosophical Transactions of the Royal Society of London. Series B, Biological Sciences, 282(1798), 20142201.

Drent, P. J., Oers, K. V., \& Noordwijk, A. J. V. (2003). Realized heritability of personalities in the great tit (Parus major). Proceedings of the Royal Society of London. Series B: Biological Sciences, 270(1510), 45-51.

Ebstein, R. P., Segman, R., Benjamin, J., Osher, Y., Nemanov, L., \& Belmaker, R. H. (1997). 5-HT2C (HTR2C) serotonin receptor gene polymorphism associated with the human personality trait of reward dependence: Interaction with dopamine D4 receptor (D4DR) and dopamine D3 receptor (D3DR) polymorphisms. American Journal of Medical Genetics, 74(1), 65-72.

Edwards, H. A., Hajduk, G. K., Durieux, G., Burke, T., \& Dugdale, H. L. (2015). No association between personality and candidate gene polymorphisms in a wild bird population. PLOS ONE 10(10), e0138439.

Eley, T. C., \& Plomin, R. (1997). Genetic analyses of emotionality. Current Opinion in Neurobiology, 7(2), 279284.

Elfwing, M., Fallahshahroudi, A., Lindgren, I., Jensen, P., \& Altimiras, J. (2014). The strong selective sweep candidate gene ADRA2C does not explain domestication related changes in the stress response of chickens. PLOS ONE 9(8), e103218.

Favati, A., Zidar, J., Thorpe, H., Jensen, P., \& Løvlie, H. (2016). The ontogeny of personality traits in the red junglefowl, Gallus gallus. Behavioral Ecology, 27(2), 484-493.

Fidler, A. E., van Oers, K., Drent, P. J., Kuhn, S., Mueller, J. C., \& Kempenaers, B. (2007). Drd4 gene polymorphisms are associated with personality variation in a passerine bird. Proceedings of the Royal Society B: Biological Sciences, 274(1619), 1685-1691.

Forkman, B., Boissy, A., Meunier-Salaün, M. C., Canali, E., \& Jones, R. B. (2007). A critical review of fear tests used on cattle, pigs, sheep, poultry and horses. Physiology \& Behavior, 92(3), 340-374.

Garamszegi, L. Z., Mueller, J. C., Marko, G., Szasz, E., Zebok, S., Herczeg, G., Eens, M., \& Török, J. (2014). The relationship between DRD4 polymorphism and phenotypic correlations of behavior in the collared flycatcher. Ecology and Evolution, 4(8), 1466-1478.

Garnham, L., \& Løvlie, H. (2018). Sophisticated fowl: the complex behavior and cognitive skills of chickens and red junglefowl. Behavioral Sciences, 8(1), 13.

Golimbet, V. E., Affimova, M. V., Manandyan, K. K., Mitushina, N. G., Abramova, L. I., Kaleda, V. G., Oleichik, I. V., Yurov, Y. B., \& Trubnikov, V. I. (2002). 5HTR2A gene polymorphism and personality traits in patients with major psychoses. European Psychiatry: The Journal of the Association of European Psychiatrists, 17(1), 24-28.

Gordon, J. A., \& Hen, R. (2004). Genetic approaches to the study of anxiety. Annual Review of Neuroscience, 27, 193-222.

Gosling, S. D. (2001). From mice to men: what can we learn about personality from animal research? Psychological Bulletin, 127(1), 45-86. 
Greggor, A. L., Thornton, A., \& Clayton, N. S. (2015). Neophobia is not only avoidance: Improving neophobia tests by combining cognition and ecology. Current Opinion in Behavioral Sciences, 6, 82-89

Gunnarsson, L., Jauhiainen, A., Kristiansson, E., Nerman, O., \& Larsson, D. G. J. (2008). Evolutionary conservation of human drug targets in organisms used for environmental risk assessments. Environmental Science \& Technology, 42(15), 5807-5813.

Heisler, L. K., \& Tecott, L. H. (2000). A paradoxical locomotor response in serotonin 5-HT2C receptor mutant mice. Journal of Neuroscience, 20(8), RC71.

Holtmann, B., Grosser, S., Lagisz, M., Johnson, S. L., Santos, E. S. A., Lara, C. E., Robertson, B. C., \& Nakagawa, S. (2016). Population differentiation and behavioral association of the two 'personality' genes DRD 4 and SERT in dunnocks (Prunella modularis). Molecular Ecology, 25(3), 706-722.

Kalueff, A. V., Gallagher, P. S., \& Murphy, D. L. (2006). Are serotonin transporter knockout mice 'depressed'?: Hypoactivity but no anhedonia. Neuroreport, 17(12), 1347-1351.

Kennett, G. A., Trail, B., \& Bright, F. (1998) Anxiolytic-like actions of BW 723C86 in the rat Vogel conflict test are 5-HT $2 \mathrm{~B}$ receptor mediated. Neuropharmacology, 37(12), 1603-1610.

Korsten, P., Mueller, J. C., Hermannstädter, C., Bouwman, K. M., Dingemanse, N. J., Drent, P. J., Liedvogel, M., Matthysen, E., van Oers, K., van Overveld, T., Patrick, S.C., Quinn, J. L., Sheldon, B. C., Tinbergen, J. M., \& Kempenaers, B. (2010). Association between DRD4 gene polymorphism and personality variation in great tits: a test across four wild populations. Molecular Ecology, 19, 832-843.

Kubikova, L., Wada, K., \& Jarvis, E. D. (2010). Dopamine receptors in a songbird brain. Journal of Comparative Neurology, 518(6), 741-769.

Kusumi, I., Suzuki, K., Sasaki, Y., Kameda, K., Sasaki, T., \& Koyama, T. (2002). Serotonin 5-HT2A receptor gene polymorphism, 5-HT2A receptor function and personality traits in healthy subjects: A negative study. Journal of Affective Disorders 68(2-3), 235-241.

Lundgren, K. A., Abbey-Lee, R. N., Garnham, L. C., Kreshchenko, A., Ryding, S., \& Løvlie, H. (2021). Manipulating monoamines reduces exploration and boldness of Mediterranean field crickets. Behavioral Processes, 183, 104298.

Malleret, G., Hen, R., Guillou, J. L., Segu, L., \& Buhot, M. C. (1999). 5-HT1B receptor knock-out mice exhibit increased exploratory activity and enhanced spatial memory performance in the Morris water maze. Journal of Neuroscience, 19(14), 6157-6168.

McBride, G., Parer, I. P., \& Foenander, F. (1969). The social organization and behavior of the feral domestic fowl. Animal Behavior Monographs 2(3), 125-181.

Mengod, G., Vilaró, M. T., Cortés, R., López-Giménez, J. F., Raurich, A., \& Palacios, J. M. (2006). Chemical neuroanatomy of 5-HT receptor subtypes in the mammalian brain. In B. L. Roth (Ed.), The Serotonin Receptors (pp. 319-364). Humana Press.

Munafo, M. R., Freimer, N. B., Ng, W., Ophoff, R., Veijola, J., Miettunen, J., Järvelin, M-R., Taanila, A., \& Fling, J. (2009). 5-HTTLPR genotype and anxiety-related personality traits: A meta-analysis and new data. American Journal of Medical Genetics. Part B, Neuropsychiatric Genetics, 150B(2), 271-281.

Munafo, M. R., Yalcin, B., Willis-Owen, S. A., \& Flint, J. (2008). Association of the dopamine D4 receptor (DRD4) gene and approach-related personality traits: Meta-analysis and new data. Biological Psychiatry, 63(2), 197206.

R Core Team. (2019). R: A language and environment for statistical computing. R Foundation for Statistical Computing, Vienna, Austria. https://www.r-project.org/

Réale, D., Reader, S. M., Sol, D., McDougall, P. T., \& Dingemanse, N. J. (2007). Integrating animal temperament within ecology and evolution. Biological Reviews, 82(2), 291-318.

Reif, A., \& Lesch, K. P. (2003). Toward a molecular architecture of personality. Behavioural Brain Research, 139(1-2), 1-20.

Riyahi, S., Sanchez-Delgado, M., Calafell, F., Monk, D., \& Senar, J. C. (2015). Combined epigenetic and intraspecific variation of DRD4 and SERT genes influence novelty seeking behavior in great tit Parus major. Epigenetics, 10(6), 516-525.

Ryding S, Garnham LC, Abbey-Lee RN, Petkova I, Kreshchenko A, Løvlie H (2021). Impulsivity is affected by cognitive enrichment, and links to brain gene expression in red junglefowl chicks. Animal Behaviour.

Schinka, J. A., Letsch, E. A., \& Crawford, F. C. (2002). DRD4 and novelty seeking: Results of meta-analyses. American Journal of Medical Genetics, 114(6), 643-648.

Schreiber, R., Melon, C., \& de Vry, J. (1998) The role of 5-HT receptor subtypes in the anxiolytic effects of selective serotonin reuptake inhibitors in the rat ultrasonic vocalization test. Psychopharmacology, 135(4), 383-391. 
Smith, B. R., \& Blumstein, D. T. (2008). Fitness consequences of personality: A meta-analysis. Behavioral Ecology, $19(2), 448-455$.

Savitz, J. B., \& Ramesar, R. S. (2004). Genetic variants implicated in personality: A review of the more promising candidates. American Journal of Medical Genetics. Part B, Neuropsychiatric genetics, 131B(1), 20-32.

Sorato, E., Zidar, J., Garnham, L., Wilson, A., \& Løvlie, H. (2018). Heritabilities and co-variation among cognitive traits in red junglefowl. Philosophical Transactions of the Royal Society of London. Series B, Biological Sciences, 373(1756), 20170285.

Soubrié, P. (1986). Reconciling the role of central serotonin neurons in human and animal behavior. Behavioral Brain Sciences, 9(2), 319-364.

Suomi, S. J. (2006). Risk, resilience, and gene x environment interactions in rhesus monkeys. Annals of the New York Academy of Sciences, 1094, 52-62.

Swallow, J. G., Bubak, A. N., \& Grace, J. L. (2016). The role of monoamines in modulating behavior. Current Zoology, 62(3), 253-255.

Tatarczyńska, E., Kłodzińska, A, Stachowicz, K, \& Chojnacka-Wójcik, E. (2004). Effects of a selective 5-HT1B receptor agonist and antagonists in animal models of anxiety and depression. Behavioral Pharmacology, $15(8), 523-534$.

Thörnqvist, P-O., Höglund, E., \& Winberg, S. (2015). Natural selection constrains personality and brain gene expression differences in Atlantic salmon (Salmo salar). Journal of Experimental Biology, 218(7), 10771083.

Vallone, D., Picetti, R., \& Borrelli, E. (2000). Structure and function of dopamine receptors. Neuroscience and Biobehavioral Reviews, 24(1), 125-132.

van Oers, K., de Jong, G., van Noordwijk, A. J., Kempenaers, B., Drent, P. J. (2005). Contribution of genetics to the study of animal personalities: A review of case studies. Behaviour, 142(9-10), 1185-1206.

van Oers, K., Mueller, J. C. (2010). Evolutionary genomics of animal personality. Philosophical Transactions of the Royal Society of London. Series B, Biological Sciences, 365, 3991-4000.

Van Oers, K. \& Sinn, D. (2013). Quantitative and molecular genetics of animal personality. In C. Carere \& D. Maestripieri (Edd.), Animal personalities (pp. 149-200). University of Chicago Press.

von Eugen, K., Tabrik, S., Güntürkün, O., \& Ströckens, F. (2020). A comparative analysis of the dopaminergic innervation of the executive caudal niopallium in pigeon, chicken, zebra finch and carrion crow. Journal of Comparative Neurology, 528(17), 2929-2955.

Wilson, D. S., Clark, A. B., Coleman, K., \& Dearstyne, T. (1994). Shyness and boldness in humans and other animals. Trends in Ecology \& Evolution, 9(11), 442-446.

Winberg, S., \& Nilsson, G. E. (1993). Roles of brain monoamine neurotransmitters in agonistic behavior and stress reactions, with particular reference to fish. Comparative Biochemistry and Physiology Part C: Pharmacology, Toxicology and Endocrinology, 106(3), 597-614.

Xiao, J., Kannan, G., Jones-Brando, L., Bannock, C., Krasnova, I. N., Cadet, J. L., Pletnikov, M., \& Yolken, R. H. (2012). Sex-specific changes in gene expression and behavior induced by chronic Toxoplasma infection in mice. Neuroscience, 206, 39-48.

Zidar, J., Balogh, A., Favati, A., Jensen, P., Leimar, O., \& Løvlie, H. (2017). A comparison of animal personality and coping styles in the red junglefowl. Animal Behaviour, 130, 209-220.

Zidar, J., Sorato, E., Malmqvist, A., Jansson, E., Rosher, C., Jensen, P., Favati, A., \& Løvlie, H. (2017). Early experience affects adult personality in the red junglefowl: A role for cognitive stimulation? Behavioural Processes, 134, 78-86.

Zidar, J., Balogh, A., Favati, A., Jensen, P., Leimar, O., Sorato, E., \& Løvlie, H. (2018). The relationship between learning speed and personality is age-and task-dependent in red junglefowl. Behavioral Ecology and Sociobiology, 72, 168.

Zidar, J., Campderrich, I., Jansson, E., Wichman, A., Winberg, S., Keeling, L., \& Løvlie, H. (2018). Environmental complexity buffers against stress-induced negative judgement bias in female chickens. Scientific Reports, 8 , 5404. 